\title{
Structural Heterogeneities in Southeast Tibet: Implications for Regional Flow in the Lower Crust and Upper Mantle
}

\author{
Zhi Wang, ${ }^{1,2}$ Xuben Wang, ${ }^{1,2}$ Runqiu Huang, ${ }^{3}$ and Wenli Huang ${ }^{2}$ \\ ${ }^{1}$ State Key Laboratory of Oil and Gas Reservoir Geology and Exploitation, Chengdu University of Technology, Chengdu 610059, China \\ ${ }^{2}$ Key Laboratory of Earth Exploration and Information Techniques, Ministry of Education, Chengdu 610059, China \\ ${ }^{3}$ State Key Laboratory of Geohazards Prevention and Geoenvironment Protection, Chendgu University of Technology, \\ Chengdu 610059, China \\ Correspondence should be addressed to Zhi Wang, mike-wang@sohu.com
}

Received 19 July 2011; Revised 3 November 2011; Accepted 23 November 2011

Academic Editor: Sheng-Rong Song

Copyright ( $\odot 2012$ Zhi Wang et al. This is an open access article distributed under the Creative Commons Attribution License, which permits unrestricted use, distribution, and reproduction in any medium, provided the original work is properly cited.

Our seismic study together with the MT analysis reveal a "R-shape" flow existing in both the lower crust and uppermost mantle, which suggests the crustal deformation along the deep, large sutures (such as the Longmen Shan fault and the Anninghe Fault) under the southeastern Tibetan Plateau is maintained by dynamic pressure from the regional flow intermingled with the hot upwelling asthenosphere. The material in the lower crust and uppermost mantle flowing outward from the center of the plateau is buttressed by the old, strong lithosphere that underlies the Sichuan basin, pushing up on the crust above and maintaining steep orogenic belt through dynamic pressure. We therefore consider that the "R-shape" regional flow played a key role in the crustal deformation along the deep suture zones of the Bangong-Nujiang, the Longmen-Shan faults, and other local heavily faulted zones beneath the southeastern Tibetan Plateau.

\section{Introduction}

The southeastern Tibetan Plateau has a very complex structure and tectonics (Figure 1), where several tectonic blocks, including the Sichuan basin, the Songpan-Ganzi block, the Qiangtang Block (including the Chuan-Dian Fragment), and the Indochina Block, are interacting with each other [1-6]. It is a site of important processes including strong compressional deformation with crust shortening and thickening, and east-west crustal extension associated with the India-Asia collision and its abutment against the stable Sichuan basin $[1,3,4]$. Previous studies have been made of the crust and upper mantle structure in the STP using various approaches. The Geological and Geodetic studies show that the crustal blocks move clockwise along the margins of the STP [7-11]. The local tomography models show the three-dimensional (3D) structure down to a maximum of about $80 \mathrm{~km}$ depth because local earthquakes occur at depths shallower than $45 \mathrm{~km}$ under this region $[5,6,8,12]$. Although global tomographic studies imaged velocity anomalies in the upper mantle, the detailed structure in the crust was not imaged $[13,14]$. Tomographic and MT researchers revealed wide-scale existence of lower crustal fluids in middle and southeastern Tibet. They suggest that uplift and crustal thickening of the STP has been supported by the stable lithosphere of the Sichuan basin through the influx of the crustal flow $[6,15]$. It should be noted that the existence of lower crustal flow would be characterized as low seismic velocity $\left(V_{p}, V_{s}\right)$ and low electrical resistivity, compared with a stable continental crust. Therefore, determining high-resolution 3D $V_{p}$ and $V_{s}$ models of both the crust and upper mantle is crucial for a better understanding of the spatial distribution of the regional flow beneath the STP.

The relationship between the Songpan-Ganzi fold system (block) and the Longmen-Shan thrust belt deformation developing at a continental plate boundary, and the reason for the development of an orogenic plateau away from that boundary are still unclear in continental dynamics. In order to investigate the features of the crustal and upper mantle flow beneath the STP and its implication on the crustal deformation along the deep, large sutures, we determined the $3 \mathrm{D}$ high resolution seismic velocity and 2D magnetotelluric 


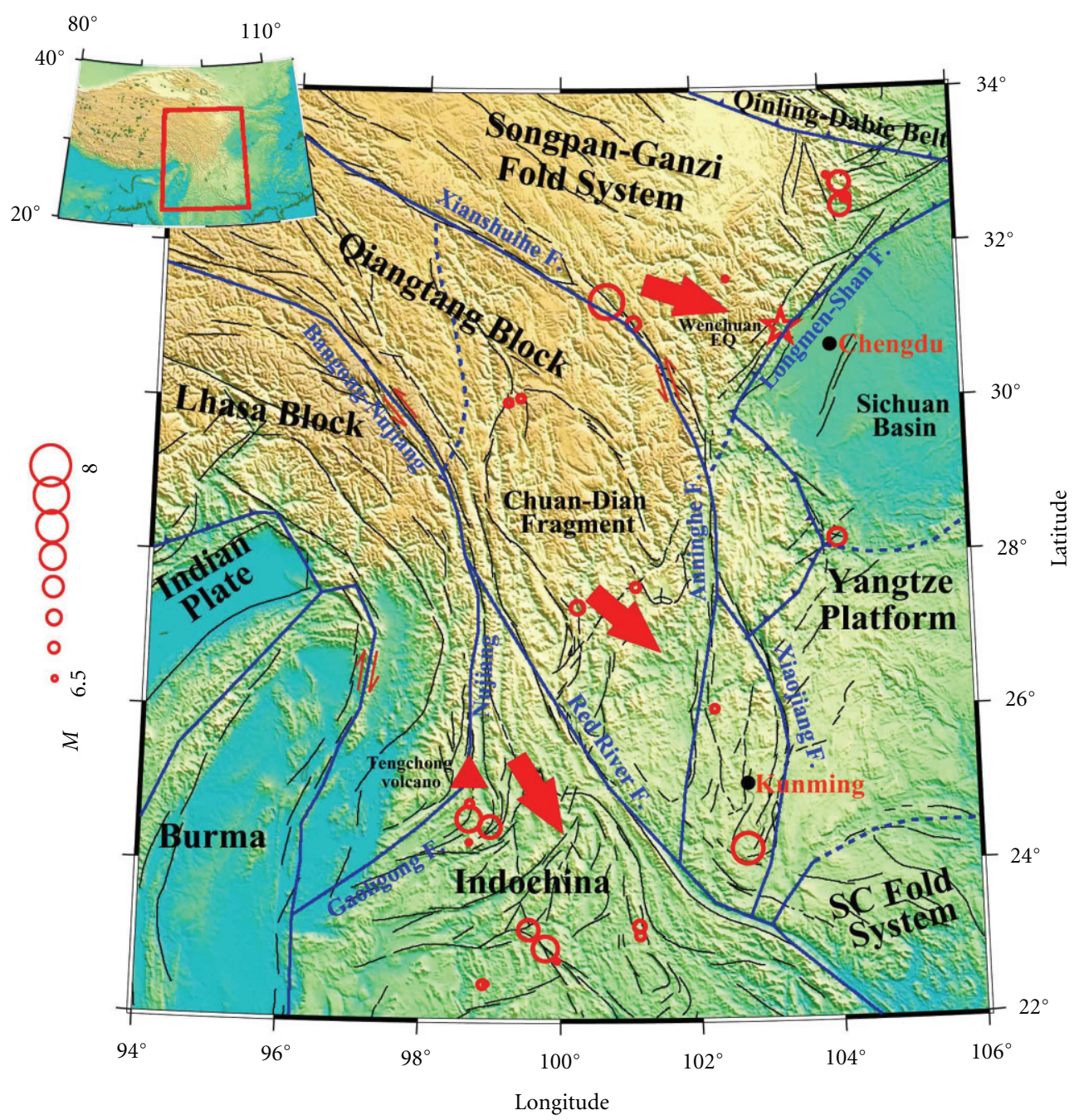

FIgURE 1: Topography and tectonic framework of the Southeastern Tibetan Plateau. Blue solid lines indicate the deep, large sutures, and main tectonic boundaries. Black thin lines show the active faults. Red open circles show the locations of the large historic earthquakes $(M>6.5)$ occurred from 1913 to 2008. Three red arrows indicate the rotation directions of the Songpan-Ganzi fold system, the Qiangtang and Indochina Blocks, respectively. Magnitude scale of the earthquakes is shown on the left. A red box in the inset map shows the present study region.

(MT) images in the crust and upper mantle using a large number of $\mathrm{P}$-wave and S-wave arrival times from both local and teleseismic events. We believe that the $V_{p}$ and $V_{s}$ models together with the MT profile, along with the previous electrical parameters, could provide important evidence for a better understanding of the spatial distribution of the flow materials in the lower crust and uppermost mantle as well as crustal deformation.

\section{Data and Method}

We collected a large number of P-wave and S-wave arrival times from local earthquakes and teleseismic events that occurred during the period from January 1985 to December 2007 (Tables 1 and 2). Arrival times for local earthquakes were collected according to the following criteria: earthquakes occurring in the study region with depths shallower than $80 \mathrm{~km}$ and magnitudes greater than Mb 1.5; earthquakes where epicentral distances were limited in the range of $0-$ $2^{\circ}$ for $\mathrm{P}$ and $\mathrm{S}$ phases and $3-6^{\circ}$ for $\mathrm{Pn}$ and $\mathrm{Sn}$ arrivals. In the epicentral distance range of $3-6^{\circ}$, the Pn and Sn become the first arrivals and their arrival times can be identified clearly from the $\mathrm{P}$ and $\mathrm{S}$ phases. The travel time residuals from $-3.0 \mathrm{~s}$ to $+3.0 \mathrm{~s}$ for $\mathrm{P}$ and $\mathrm{Pn}$ waves and from $-4.0 \mathrm{~s}$ to $+4.0 \mathrm{~s}$ for $\mathrm{S}$ and $\mathrm{Sn}$ phases were used in the tomographic inversion. In total, $140,341 \mathrm{P}$ and $\mathrm{Pn}$ phases and 114,268 S and Sn phases were selected from 14,474 local earthquakes recorded by more than eight seismic stations.

Because most of the local earthquakes occurred at a focal depth shallower than $50 \mathrm{~km}$ (Figure 2(a)), it is difficult to image the deep structures in the lower crust and upper mantle at high resolutions using the local arrival time data only. We therefore collected the P-wave and S-wave arrival times from teleseismic events to image the upper mantle structure 
TABLE 1: Detailed information on the local-earthquake arrival-time data and seismic arrays (see text for details).

\begin{tabular}{lccccc}
\hline Arrays & Stations & Events & \multicolumn{2}{c}{ Arrival times } & Duration of experiment \\
\hline IGCEA & 29 & 4,278 & 43,265 & 37,423 & Jan. 1985-Dec. 2007 \\
SC & 56 & 7,005 & 66,643 & 50,790 & Jan. 2000-Dec. 2007 \\
YN & 60 & 1,620 & 14,211 & 12,852 & Nov. 1999-Aug. 2007 \\
ISC & 14 & 1,478 & 12,544 & 9,862 & Jan. 1991-Dec. 2006 \\
XE and YA & 73 & 61 & 3,361 & 3,056 & July 2003-Dec. 2004 \\
XC & 19 & 32 & 317 & 285 & June 1991-April 2002 \\
\hline Total & 254 & 14,474 & 140,341 & 114,268 &
\end{tabular}

TABLE 2: Seismic stations and relative arrival times from teleseismic events (see text for details).

\begin{tabular}{|c|c|c|c|c|c|}
\hline \multirow{2}{*}{ Arrays } & \multirow{2}{*}{ Stations } & \multirow{2}{*}{ Events } & \multicolumn{2}{|c|}{ Relative arrival times } & \multirow{2}{*}{ Duration of experiment } \\
\hline & & & $\mathrm{P}$ & S & \\
\hline SC and YN & 40 & 156 & 5,619 & 5,176 & Nov. 1999-Aug. 2007 \\
\hline ISC & 14 & 4,283 & 32,791 & 26,254 & Jan. 1991-Dec. 2006 \\
\hline $\mathrm{XE}$ and $\mathrm{YA}$ & 73 & 174 & 9,196 & 6,753 & July 2003-Dec. 2004 \\
\hline $\mathrm{XC}$ & 19 & 169 & 1,567 & 1,389 & June 1991-April 2002 \\
\hline Total & 135 & 4,782 & 49,173 & 39,572 & \\
\hline
\end{tabular}

under the STP (Figure 2(b)). We handpicked 16,382 $\mathrm{P}$ phases and $13,318 \mathrm{~S}$ phases from the four portable seismic arrays along with 40 stations deployed by the SYSB (Table 2). The selected teleseismic events have a fairly complete azimuthal coverage (Figure 2(b)). All the teleseismic events recorded by more than nine seismic stations are at epicentral distances between $30^{\circ}$ and $90^{\circ}$, thus removing the influences of complex structures of the core-mantle boundary and the upper mantle outside of the study area. In total, 49,173 $\mathrm{P}$-wave and 39,572 S-wave relative arrivals, including the arrival time data from ISC were collected from the 4,782 teleseismic events with magnitude $(\mathrm{Mb})$ greater than 5.5. The relative travel time residuals ranging from $-3.0 \mathrm{~s}$ to $+3.0 \mathrm{~s}$ for P-wave and $-4.0 \mathrm{~s}$ to $+4.0 \mathrm{~s}$ for S-wave are used in the tomographic inversion. In this study, a joint tomographic inversion method [16] has been used to analyze the local and teleseismic data simultaneously for determining the 3D $V_{p}$ and $V_{s}$ structures of the crust and upper mantle in the STP. The absolute arrival time data for local earthquakes are used for the hypocenter location and tomographic inversion simultaneously while the relative travel time residuals for the teleseismic events are used to invert to determine the upper mantle structure. Thus the effects of the uncertainties in the hypocenter parameters of the teleseismic events and the effects of the structural heterogeneities outside of the study region can be avoided.

In this study we used 254 seismic stations for seismic tomography (Figure 2(a)). These stations included four temporal seismic arrays and four permanent seismic networks. The temporal seismic arrays included the Namche Barwa Tibet (XE) seismic array; the MIT-China (YA) seismic array; the Namche Barwa-Tibet Pilot Experiment (XC2002); the Tibetan Plateau Broadband Experiment (XC1991). The permanent networks are deployed by the Sichuan and Yunnan Seismological Bureaus (SYSB), the Institute of Geophysics of China Earthquake Administration (IGCEA) and the International Seismological Center (ISC) (Tables 1 and 2).

The 1-D initial velocity model was determined by two steps. At the shallower depths of the crust, the $V_{p}$ and $V_{s}$ initial models are derived from the recent local tomography and receiver function studies $[5,16]$. In the upper mantle, the $V_{p}$ and $V_{s}$ initial values are taken from the IASP91 model [17]. An optimal 1D velocity model was then calculated with inhomogeneous velocities in each of the layers of laterally varying thicknesses (Figure 3(a)). When we determined the optimal 1D $V_{p}$ and $V_{s}$ models, the earthquakes with over $10 \mathrm{P}$-wave and $9 \mathrm{~S}$-wave arrivals were selected for the calculations with the initial P- and S-wave models, respectively. Figure 3(a) shows the initial and calculated 1D velocity models. Considering the effects of the frequency content of the data, the station spacing and the ray-path spatial distributions on the final resolution, we adopted a grid model with a horizontal grid spacing of $0.5-1.0^{\circ}$ and a vertical grid spacing of 10-100 km (Figure 3(b)).

\section{Resolution Analyses}

Prior to seismic tomography, we conducted checkerboard resolution tests (CRTs) to evaluate the resolution of our 3D $V_{p}$ and $V_{s}$ models. Velocity perturbations of $\pm 2 \%$ were assigned to the grid nodes adjacent to each other, and then synthetic travel times were calculated for the checkerboard model. Figure 4 shows the plan views of the CRT results for $V_{p}$ and $V_{s}$ images at each depth, indicating that the resolution of the tomographic images is high at depths of between 25 and $90 \mathrm{~km}$. The CRT results for the $V_{p}$ 


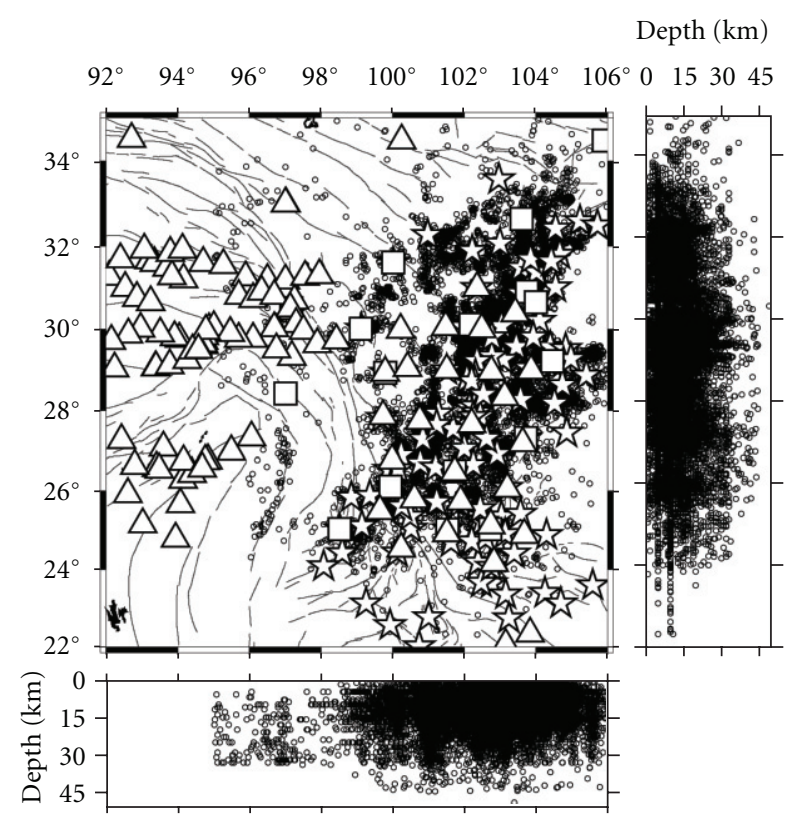

(a)

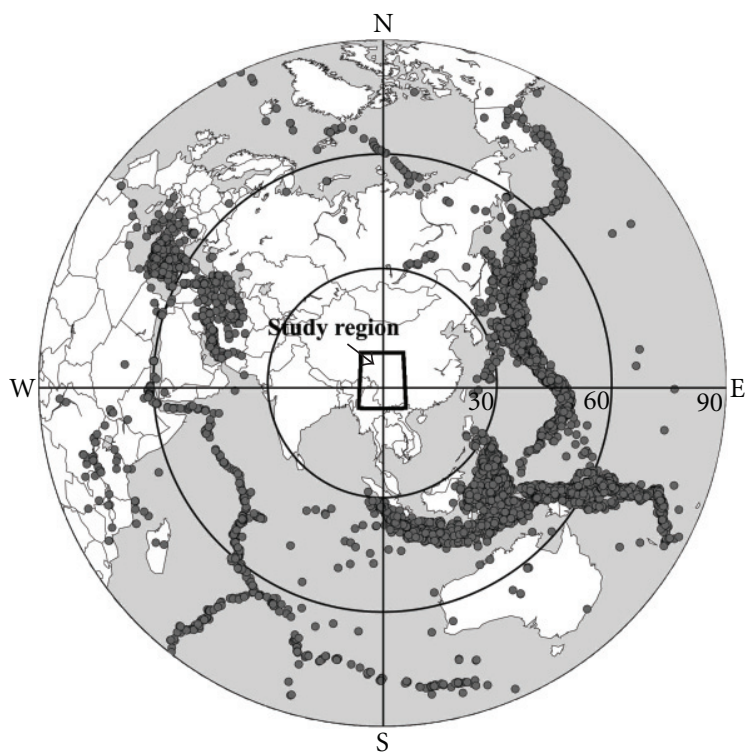

(b)

FIGURE 2: (a) 3D hypocenter distribution of local earthquakes. Black circles show the hypocenters of 14,474 local earthquakes with magnitude larger than 1.5. Open stars show the permanent stations deployed by the Seismological Bureaus of Sichuan and Yunnan Provinces. Open squares show the seismic station by the Institute of Geophysics of China Earthquake administration and the International Seismological Center (ISC). Triangles indicate the temporal seismic arrays (see Tables 1 and 2). (b) Epicenter distribution of the 4782 teleseismic events (gray dots) used in this study. The concentric circles correspond to epicentral distance of $30^{\circ}, 60^{\circ}$, and $90^{\circ}$. The black box denotes the present study region.

and $V_{s}$ models are consistent with each other (Figure 4). Although few earthquakes occurred in the lower crust and no local earthquakes occurred in the upper mantle under the study region, numerous rays of head waves (Pn, Sn) from the crustal earthquakes were refracted at the Moho discontinuity, allowing the near vertical rays from the teleseismic events to sample the lower crust and upper mantle. The checkerboard pattern in the lower crust and uppermost mantle was generally recovered, and therefore we believe that the seismic velocity variations in the study region were resolvable features.

\section{Discussion}

Figure 5 shows the plan views of $\mathrm{P}$ - and S-wave tomographic images in the crust and upper mantle together with the seismicity at each depth. The patterns of the $V_{p}$ and $V_{s}$ images are similar to each other. A lateral velocity boundary was revealed down to about $10 \mathrm{~km}$ depth along the Longmen-Shan fault zone (Figure 5), that is, low- $V$ anomalies appear in the areas to the southeast of the fault zone, corresponding to the Sichuan foreland basin, while high- $V$ anomalies are revealed in the regions to the northwest, corresponding to the Songpan-Ganzi Fold System. Similarly, in the upper mantle high- $V$ lithosphere in the foreland basin and low- $V$ anomalies of the SongpanGanzi asthenosphere are imaged with a sharp contrast across the Longmen-Shan tectonic zone. Receiver function and local tomography studies indicated that low- $V$ layers with high Poisson's ratio exist not only in the middle crust (at $16 \mathrm{~km}$ depth) but also in the lower crust $[5,16,19,20]$. All these features are supported by a geophysical modeling [4] and a recent crustal stress study [20] in the Longmen mountain and its surrounding regions.

Figures 6 and 7 show the vertical profiles across the deep, large sutures of the Bangong-Nujiang, the Xianshuihe, the Anninghe (Figure 6), and the Longmen-Shan fault (Figure 7). Strong low velocity zones are clearly imaged beneath the deep, large sutures at the depths of the lower crust and uppermost mantle. The low velocity zone extends up to $100 \mathrm{~km}$ depth under the Songpan-Ganzi and Qiangtang blocks (profiles L1 and L2 in Figure 6 and sections L2 and L3 in Figure 7). However, the extended depth is shallower than $80 \mathrm{~km}$ near the Sichuan basin (section L2 and L3 in Figure 6 and profile L1 in Figure 7). Figure 8 indicates the plan view of the low velocity anomalies along the Moho discontinuity. The depth of the low velocity zone varies from the lower crust to the uppermost mantle. Two low velocity zones are clearly imaged: one zone is along the Bangong-Nujiang and the Nujiang sutures; another zone runs along the Xianshuihe fault, the Anninghe fault, and then turns eastward along the edge portion of the south Sichuan basin (Figure 8 ). The feature of the low velocity zone along two channels imaged from the seismic tomography is similar to that revealed by magnetotelluric soundings, which is interpreted to be the low velocity zones with high 


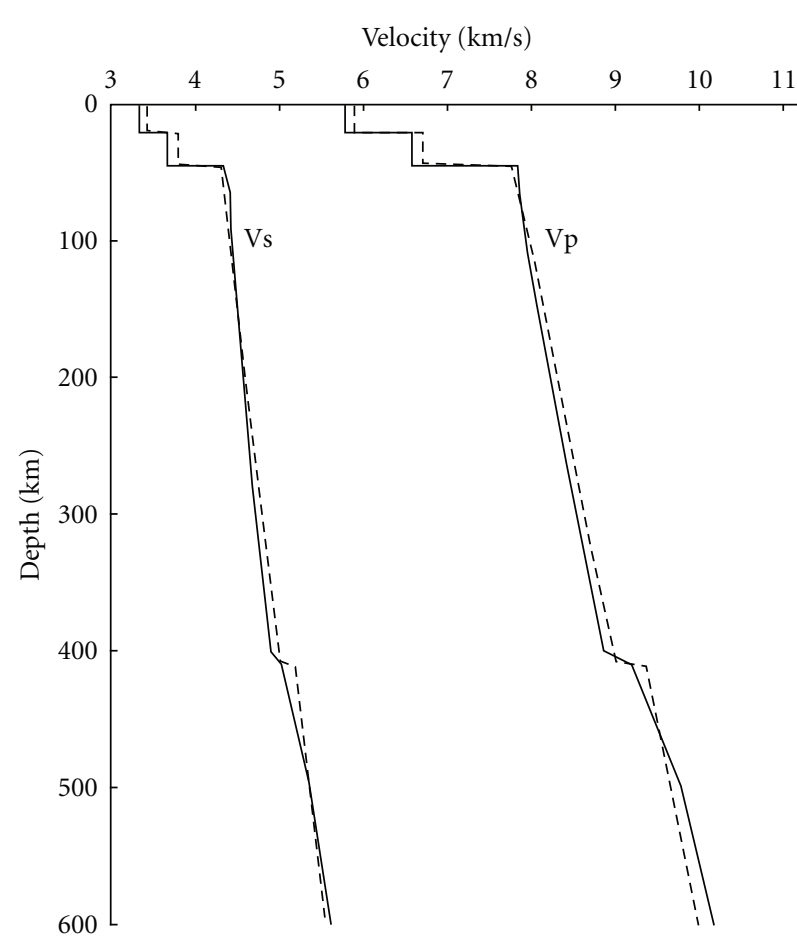

(a)

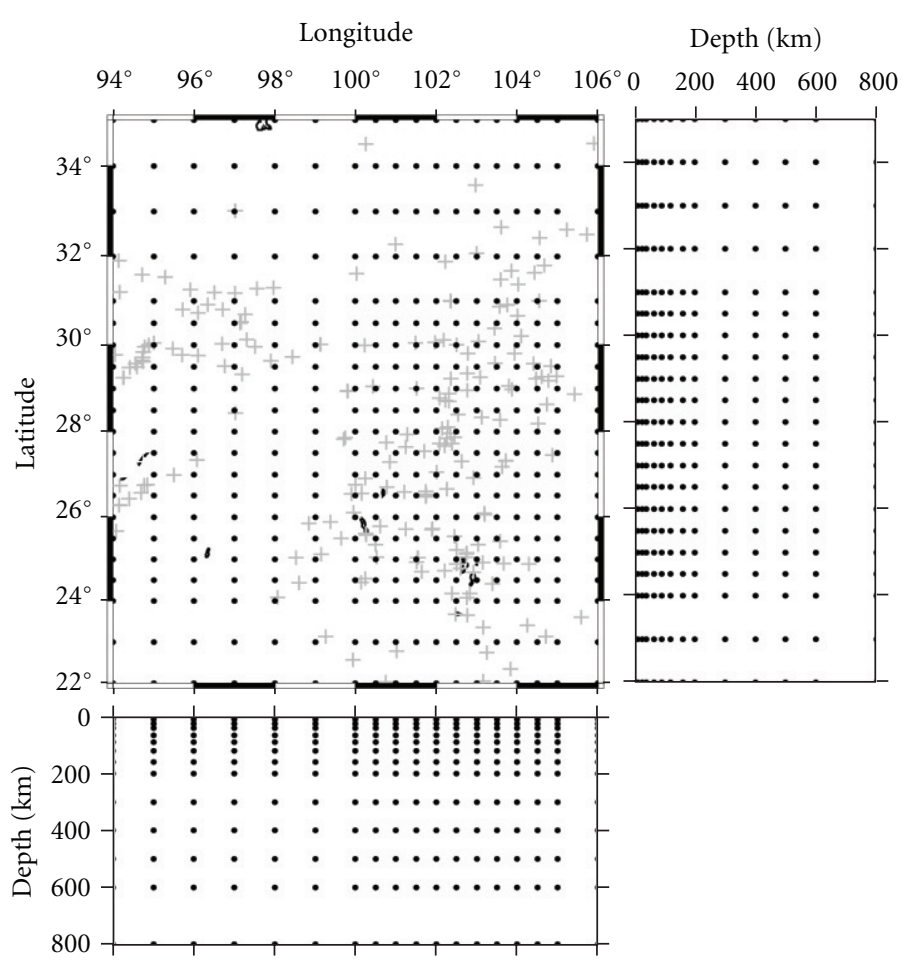

(b)

Figure 3: (a) 1D velocity models. The solid lines show the optimal $V_{p}$ and $V_{s}$ velocity models used in this study. The short dashed lines indicate the initial velocity model inferred from the previous tomographic and receiver function studies [5, 16] and the IASP91 model [17]. (b) The grid model adopted for the final tomographic inversion. The grid spacing is $50-100 \mathrm{~km}$ in N-S and E-W directions and 10-200 km in depth. Gray crosses denote the seismic stations. In areas with more seismic stations, a smaller grid spacing is adopted.

electrical conductivity as channel flow $[15,21]$. We consider that the lateral low velocity zone under the Qiangtang and Songpan-Ganzi blocks could be lateral flow in the lower crust and uppermost mantle, and the two branches of low velocity zones along the Nujiang suture and the edges of the southwestern Sichuan basin could be channel flow (Figure 8).

Our seismic study indicates that the low velocity zones are not only constrained in the lower crust above the Moho discontinuity but are also imaged in the uppermost mantle (Figures 6-8), similar to mantle flow under a continent determined through previous studies $[22,23]$. The higher conductivity anomalies found in the lower crust and upper mantle are consistent with the Plio-Pleistocene volcanic rocks associated with delimitation and derivation of the upper mantle in northern Tibet $[24,25]$. The high electrical conductivity of the upper mantle is consistent with a region of low seismic velocities with high attenuation found in northern Tibet [26]. The depth of the flow is different from those revealed by the previous studies which suggest the channel flow is along the Moho boundary in the lower crust $[15,18,27]$. The degree of rheological stratification which dictates crust-mantle coupling strongly influences the behavior of the lithosphere during deformation by controlling how strain is vertically partitioned $[2,28]$. We consider that the low velocity zones in both the lower crust and uppermost mantle as a reliable feature because (1) a large number of arrival times are used from both local and teleseismic events which effectively sample the lower crust and uppermost mantle (Figure 2); (2) the CRT results show high resolution along the two deep, large sutures at these depths (Figure 4). The previous studies suggest that a weak lower crustal layer is unable to support large topographic stresses and leads to a low relief plateau. The identified features of the seismic and electrical properties are to be expected if a partial melt were present. We would then suggest that the flow includes both the lower crust and uppermost mantle as evidenced by the seismic and magnetotelluric data.

Our seismic images show that lateral low velocity anomalies are imaged beneath the Qiangtang and Songpan-Ganzi blocks while channel low velocity zones are determined along the Bangong-Nujiang suture and the margin areas to the southwestern Sichuan basin (Figure 8). The previous lower crustal flow model suggests that after encountering the rheologically strong basement of the Sichuan Basin along the edge portion of the north Songpan-Ganzi block [18], crustal flow was diverted northeastward beneath the edge of the northwestern Sichuan basin. This follows the rheologically "weak" crustal corridor along the Paleozoic-Mesozoic Qinling fault zone, which leads to the dextral strike-slip along the Longmen-Shan fault zone and related second-order faults 

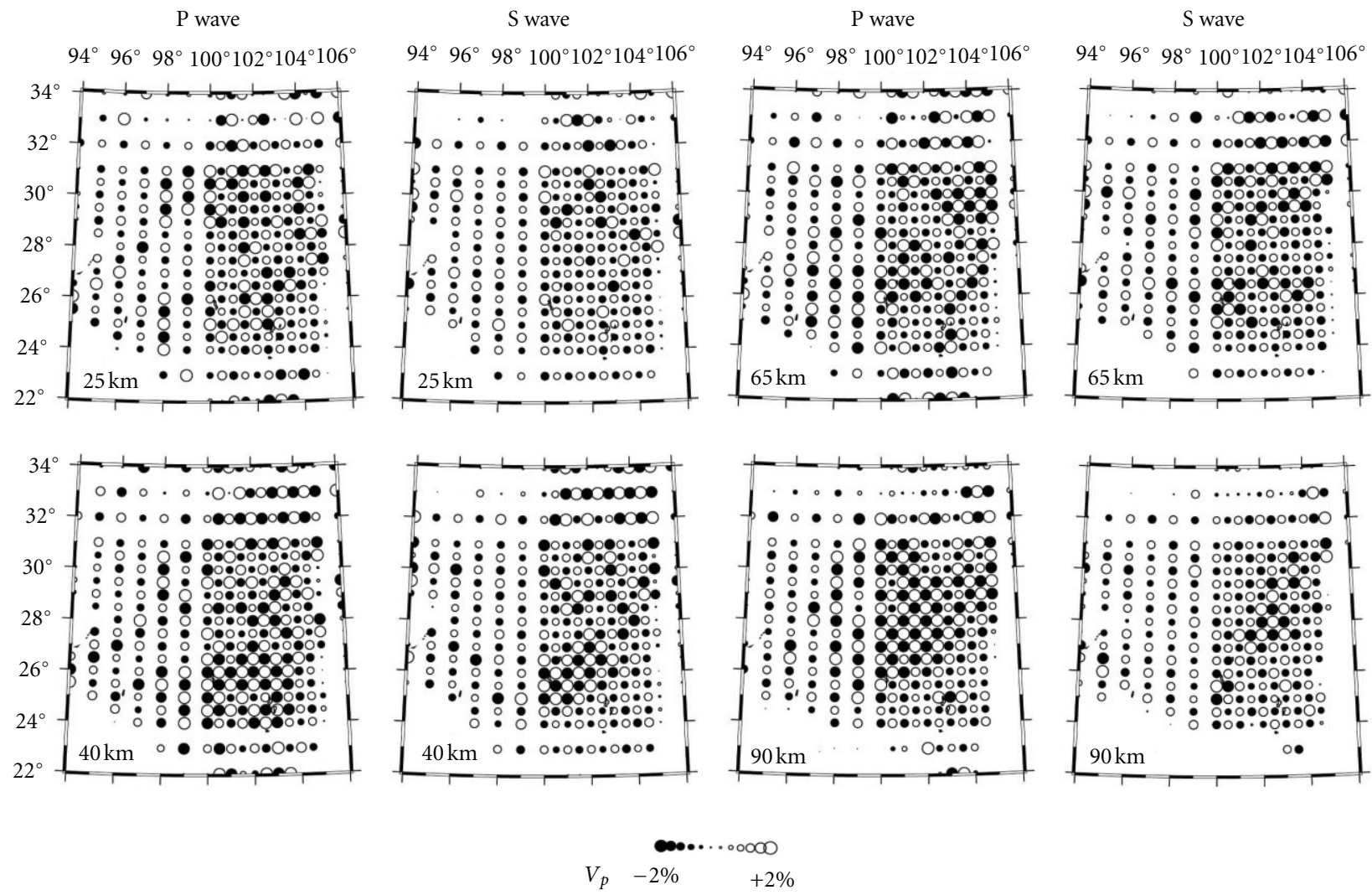

FIgURe 4: Plan views of the checkerboard resolution tests (CRTs) for the P- and S-wave tomography. The input amplitudes of the velocity perturbations are $\pm 2 \%$ at every grid nodes. The layer depth is shown at the lower-left corner of each map. The scale for the velocity perturbations (in \%) relative to the $1 \mathrm{D}$ initial velocity model is shown at the bottom.

[29]. The locations of the low velocity zones identified from our seismic images show a good correlation with the previous lower crustal flow model under the Songpan-Ganzi block and the center part of the Qiangtang block. We thus consider that there is both lateral flow and channel flow present under the north and south parts of the STP, respectively.

Recent seismic imaging and crustal stress analysis have revealed similar features of the crustal structure beneath the STP $[5,6,30]$. The low velocity zones revealed along the Moho discontinuity in the lower crust and uppermost mantle beneath the STP (Figures 6-8) show general agreement with the previous studies $[2,5,12,30]$. The magnetotelluric profiles show the high conductivity anomaly at depths of between 40 and $80 \mathrm{~km}$ under southeast Tibet [15, 22, $31,32]$, to represent the widespread existence of fluids at these depths. Satellite magnetic studies and geophysical modeling imply the existence of partial melts along the Moho boundary. This is because the elevated temperatures caused by radiogenic heating are high enough to cause melting due to the rapid variations of surface topography over a short horizontal distance across the margins of the STP $[4,33]$. We interpret the low velocity zones with high conductivity anomalies as lateral flow under the north part and channel flow beneath the south part of the STP. These are associated with the presence of fluids such as partial melt or aqueous fluids from the lower crust and upper mantle [6].

To explain the crustal deformation and widespread extensional tectonism, many models associated with crustal thinning, mantle thinning or removal, and lower crustal flow have been proposed. Based on our tomographic images along with the results of the previous studies, we propose a dynamic model for the margin regions of the STP. The flow from central Tibet intermingles with the hot upwelling asthenosphere from the upper mantle, building up the tectonic stress beneath the margins of the STP. The deeply rooted, craton-like lithosphere under the Sichuan basin forms a sharply contrasted velocity structure across the margins from the basin to the mountains [6]. The velocity anomalies revealed by this study and the spatial distribution of the crustal stress indicated by the previous study suggest that the crustal deformation is strongly coupled with the motions of the crust and upper mantle [30]. This leads to high pore pressure accumulating in the upper crust in the margins. A previous study reveals the lower fault friction within the deep and large sutures under the southeastern Tibetan margins, which leads to negligible compression across the sutures [34]. Compressional or extensional deformation observed in the surface geological record is considered to represent changes in thickness to the 

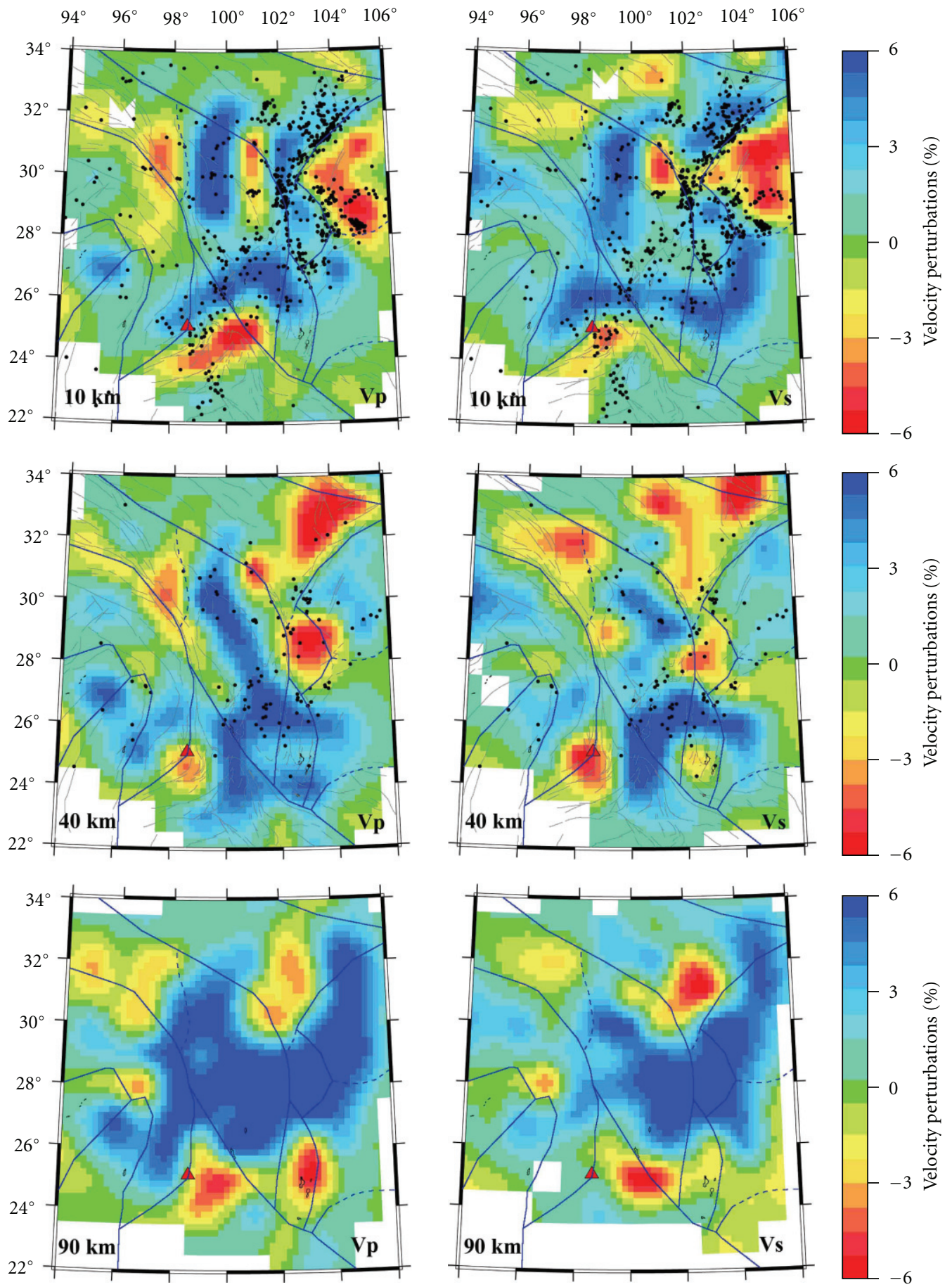

Figure 5: Plan views of P-wave and S-wave velocity images (in \%) at the depths of $10 \mathrm{~km}, 40 \mathrm{~km}$, and $90 \mathrm{~km}$. The layer depth is shown in the lower-left corner of each map. Red color denotes low velocity while blue color represents high velocity. Black dots show the epicenters of earthquakes within a range of 5-10 km along each depth. Gray solid lines indicate the active faults and blue solid lines show the major plate boundaries and sutures. A red triangle denotes the active Tengchong volcano. The velocity perturbation scale and the magnitude scale of large crustal earthquakes are shown on the upper right of the map. 


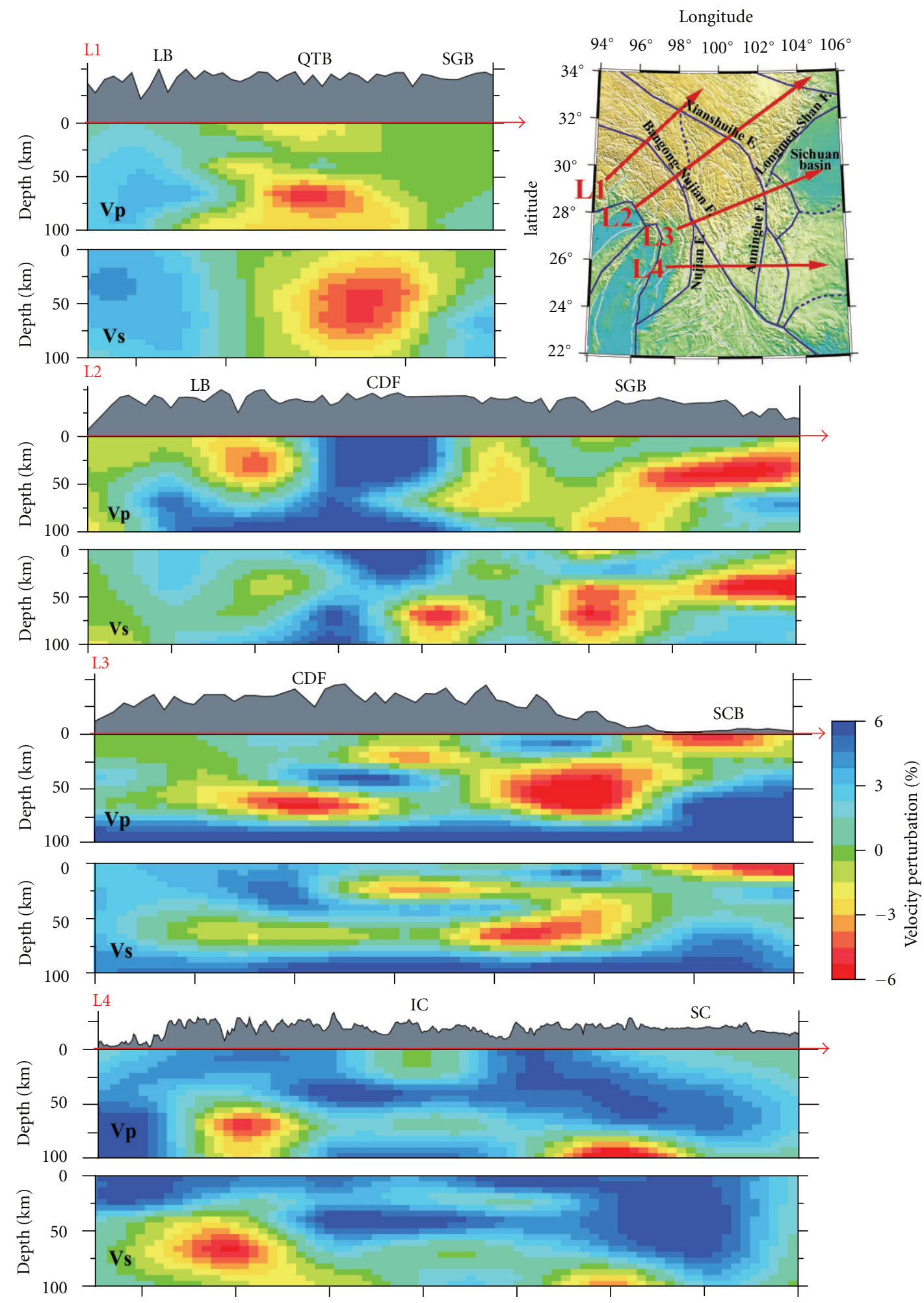

Figure 6: Vertical cross-sections of P- and S-wave velocity images along the lines shown on the upright inset map. Red color indicates low velocity while blue color denotes high velocity. The surface topography is shown on the top of each section. LB: Lhasa Block. QTB: Qiangtang Block. SGB: Songpan-Ganzi block (fold system). CDF: Chuan-Dian Fragment. SCB: Sichuan Basin. IC: Indochina. SC: South China block, LB: Lhasa block. 

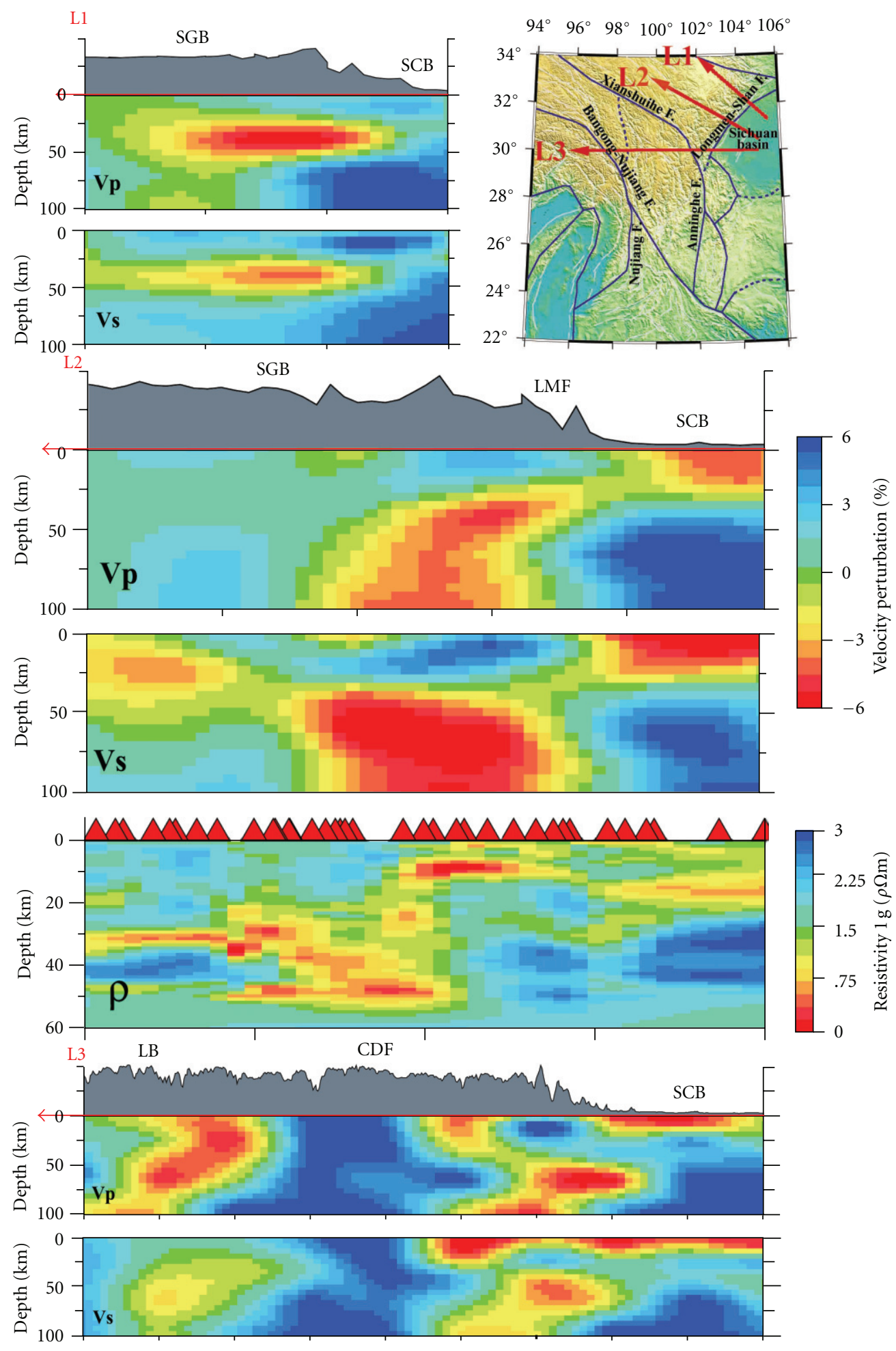

FigURE 7: Vertical cross-sections of P- and S-wave velocity images along the lines shown on the upright inset map. Red color indicates low velocity while blue color denotes high velocity. The surface topography is shown on the top of each profile. SGB: Songpan-Ganzi block (fold system). SCB: Sichuan Basin. LMF: Longmen-Shan Fault zone. LB: Lhasa Block. CDF: Chuan-Dian Fragment. 

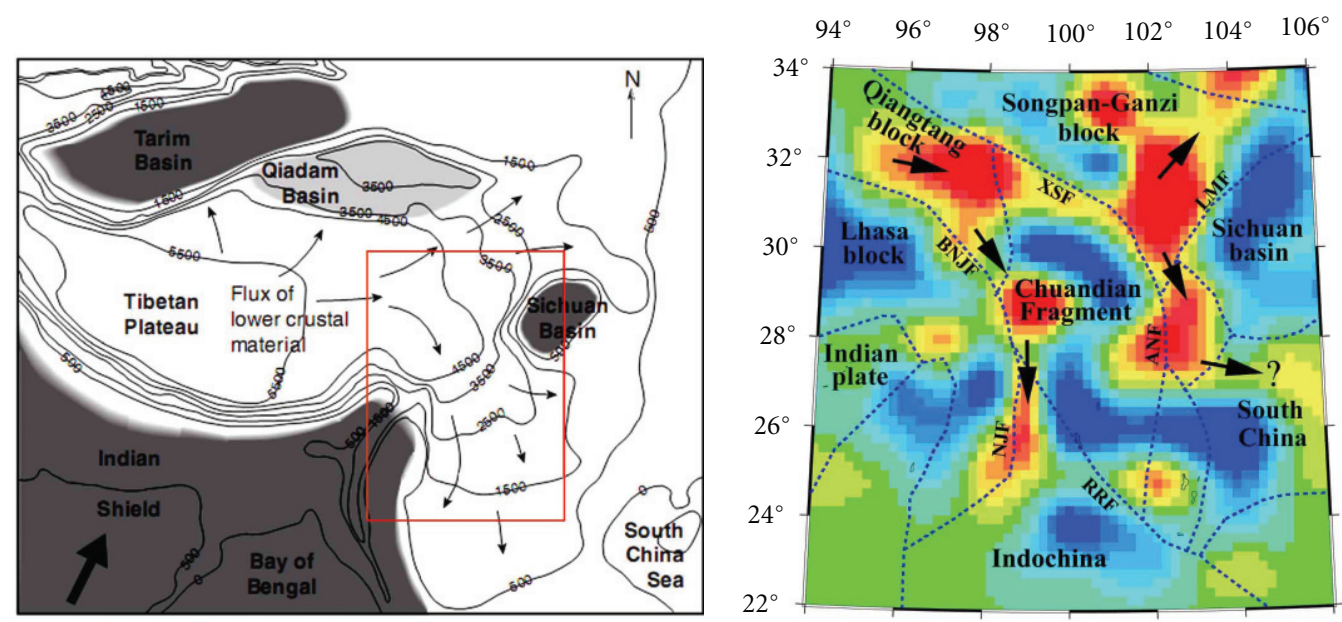

FIGURE 8: Left plan showing contour of smoothed elevations of Tibetan Plateau and surrounding regions [18]. Dark gray and light gray areas indicate regions of cold, strong, continental materials, and intermediate strength, respectively. White areas represent weak crustal regions. Right map showing low velocity anomalies (in \%) along the depth between the lower crust and uppermost mantle. Red color indicates the locations of the regional flow. Blue dashed lines show the deep, large sutures, and the main tectonic boundaries. Black arrows indicate the presumed directions of the regional flow outward from the center of the plateau. BNJF: the Bangong-Nujian suture. XSF: Xianshuihe suture. LMF: the Longmen-Shan suture. NJF: the Nujiang suture. ANF: the Anninghe suture. RRF: the red river suture.

entire crust or lithosphere beneath the deforming region. However, if material is added to the crust from mantle melts or from adjacent undeformed regions by lower crustal flow, or if material is lost from the lithosphere by mantle foundering, there may be a deficit or excess of crust or mantle material from what would otherwise be predicted from the deformation recorded in surface rocks.

The conductivity anomalies of fluids are critical to the understanding of geodynamic processes, fluid is thus considered to be an important factor for crustal flow $[5,35,36]$. Fluid conductivity is sensitive to pressure, composition, and temperature [37]. Experimental data show that the electrical conductivity of wet rocks containing $0.01 \% \mathrm{H}_{2} \mathrm{O}$ is hundreds of times higher than dry rocks at a temperature of $1000 \mathrm{~K}$ [38]. The conductivity of pure melt is typically of $1-10 \mathrm{~S} \mathrm{~m}^{-1}$ for dry rocks of various compositions [39]. Geodynamic modeling and seismic studies providing indirect information on temperatures in the crust suggest that they could be as low as $700 \mathrm{~K}$ in the study region. In the continental crust, crustal melting, or partial melting occurred at a temperature of 900 $1200^{\circ} \mathrm{C}$ for the dry solidus and $700-800^{\circ} \mathrm{C}$ for the hydrated solidus. If fluids extrude into the solidus, the melting temperature decreases dramatically to less than $700^{\circ} \mathrm{C}[40-$ 43]. These lines of evidence indicate that the temperature in the middle-lower crust is too low for the dry rocks, but hydrous melting is possible and a melt conductivity in the order of $1-10 \mathrm{~S} \mathrm{~m}^{-1}$ is to be expected [39]. Therefore, according to previous studies [43], the temperature in the fluid bearing areas in the STP is high enough to cause melting or partial melting due to the presence of fluids in the crustal solidus. We conclude that crustal deformation in the margin regions of the STP is maintained by the tectonic stress from the fluid bearing flow along the Moho boundary in both the lower crust and the uppermost mantle. This is because the material flowing outward from the center of the plateau is buttressed by the old and strong cratonic lithosphere beneath the Sichuan basin $[3,6]$, pushing up on the crust above and maintaining steep topography through dynamic pressure in the edge portions of the STP.

\section{Conclusions}

Our tomographic study indicates the existence of an " $R$ shape" regional flow in the lower crust and uppermost mantle beneath the STP. The spatial distribution of the channel flows coincide well with the great deep sutures, such as the Bangong-Nujiang fault; the Xianshuihe fault; the Longmen-Shan fault; the Anninghe fault, indicating the close relationship between the channel flow and the deep fault structures. The crustal deformation along the sutures, for example, along the Longmen-Shan fault, is maintained by dynamic pressure from the regional channel flow intermingling with the hot upwelling asthenosphere. The material in the lower crust and uppermost mantle flowing outward from the center of the plateau is buttressed by the old, strong lithosphere that underlies the Sichuan basin, pushing up on the crust above and maintaining the steep topography by dynamic pressure. We thus suggest that the "R-shape" regional flow plays a key role on crustal deformation along the deep and large suture zones.

\section{Acknowledgments}

The authors appreciate (the Editor) S. Song and one anonymous reviewer for their constructive comments on the presentation which was much improved during the revision process. They thank Drs. Pei and Wang for providing them the arrival-time data recorded by the seismic stations of the Seismological Bureaus of Sichuan and Yunnan provinces and 
the Institute of Geophysics of China Earthquake Administration. They thank the staffs of the temporal seismic arrays and the IRIS data center for providing the seismic data used in the present study. This work was partially supported by the Projects sponsored by NSFC (40872148, 40974024, 40839909, 40972087, and 41030426) and the Research Grants (NCET-10-0887, KYTD201002, 2010JQ0033). They are also grateful to the Cultivating Program of excellent innovation team of Chengdu University of Technology for supporting this work.

\section{References}

[1] P. Molnar and P. Tapponnier, "Active tectonics of Tibet," Journal of Geophysical Research, vol. 83, no. B11, pp. 53615375, 1978.

[2] L. H. Royden, B. C. Burchfiel, R. W. King et al., "Surface deformation and lower crustal flow in eastern Tibet," Science, vol. 276, no. 5313, pp. 788-790, 1997.

[3] L. H. Royden, B. C. Burchfiel, and R. D. Van Der Hilst, "The geological evolution of the Tibetan plateau," Science, vol. 321, no. 5892, pp. 1054-1058, 2008.

[4] M. K. Clark, J. W. M. Bush, and L. H. Royden, "Dynamic topography produced by lower crustal flow against rheological strength heterogeneities bordering the Tibetan Plateau," Geophysical Journal International, vol. 162, no. 2, pp. 575-590, 2005.

[5] Z. Wang, Y. Fukao, and S. Pei, "Structural control of rupturing of the Mw7.9 2008 Wenchuan Earthquake, China," Earth and Planetary Science Letters, vol. 279, no. 1-2, pp. 131-138, 2009.

[6] Z. Wang, D. Zhao, and J. Wang, "Deep structure and seismogenesis of the north-south seismic zone in southwest China," Journal of Geophysical Research B, vol. 115, no. 12, Article ID B12334, 19 pages, 2010.

[7] Z. Chen, B. C. Burchfiel, Y. Liu et al., "Global Positioning System measurements from eastern Tibet and their implications for India/Eurasia intercontinental deformation," Journal of Geophysical Research B, vol. 105, no. 7, pp. 16215-16227, 2000.

[8] C. Y. Wang, W. W. Chan, and W. D. Mooney, "Threedimensional velocity structure of crust and upper mantle in southwestern China and its tectonic implications," Journal of Geophysical Research B, vol. 108, no. 9, pp. 13-15, 2003.

[9] P. Z. Zhang, Z. Shen, M. Wang et al., "Continuous deformation of the Tibetan Plateau from global positioning system data," Geology, vol. 32, no. 9, pp. 809-812, 2004.

[10] Z. Niu, M. Wang, H. Sun et al., "Contemporary velocity field of crustal movement of Chinese mainland from Global Positioning System measurements," Chinese Science Bulletin, vol. 50, no. 9, pp. 939-941, 2005.

[11] W. Gan, P. Zhang, Z. K. Shen et al., "Present-day crustal motion within the Tibetan Plateau inferred from GPS measurements," Journal of Geophysical Research B, vol. 112, no. 8, Article ID B08416, 2007.

[12] J. Huang, D. Zhao, and S. Zheng, "Lithospheric structure and its relationship to seismic and volcanic activity in southwest China," Journal of Geophysical Research B, vol. 107, no. 10, article 2255, 14 pages, 2002.

[13] C. Li, R. D. van der Hilst, and M. N. Toksöz, "Constraining P-wave velocity variations in the upper mantle beneath Southeast Asia," Physics of the Earth and Planetary Interiors, vol. 154, no. 2, pp. 180-195, 2006.
[14] C. Li, R. D. van der Hilst, A. S. Meltzer, and E. R. Engdahl, "Subduction of the Indian lithosphere beneath the Tibetan Plateau and Burma," Earth and Planetary Science Letters, vol. 274, no. 1-2, pp. 157-168, 2008.

[15] D. Bai, M. J. Unsworth, M. A. Meju et al., "Crustal deformation of the eastern Tibetan plateau revealed by magnetotelluric imaging," Nature Geoscience, vol. 3, no. 5, pp. 358-362, 2010.

[16] L. Xu, S. Rondenay, and R. D. van der Hilst, "Structure of the crust beneath the southeastern Tibetan Plateau from teleseismic receiver functions," Physics of the Earth and Planetary Interiors, vol. 165, no. 3-4, pp. 176-193, 2007.

[17] B. L.N. Kennett and E. R. Engdahl, "Traveltimes for global earthquake location and phase identification," Geophysical Journal International, vol. 105, no. 2, pp. 429-465, 1991.

[18] M. K. Clark and L. H. Royden, "Topographic ooze: building the eastern margin of Tibet by lower crustal flow," Geology, vol. 28, no. 8, pp. 703-706, 2000.

[19] J. F. Hu, Y. L. Hu, J. Y. Xia, Y. Chen, H. Zhao, and H. Y. Yang, "Crust-mantle velocity structure of $\mathrm{S}$ wave and dynamic process beneath Burma Arc and its adjacent regions," Chinese Journal of Geophysics (Acta Geophysica Sinica), vol. 51, no. 1, pp. 140-148, 2008.

[20] R. Huang, Z. Wang, S. Pei, and Y. Wang, "Crustal ductile flow and its contribution to tectonic stress in Southwest China," Tectonophysics, vol. 473, no. 3-4, pp. 476-489, 2009.

[21] Z. Wang, J. Wang, Z. Chen et al., "Seismic imaging, crustal stress and GPS data analyses: implications for the generation of the 2008 Wenchuan Earthquake (M7.9), China," Gondwana Research, vol. 19, no. 1, pp. 202-212, 2011.

[22] F. Pollitz, M. Vergnolle, and E. Calais, "Fault interaction and stress triggering of twentieth century earthquakes in Mongolia," Journal of Geophysical Research B, vol. 108, no. 10, article 2503, 14 pages, 2003.

[23] B. M. Kennedy and M. C. Van Soest, "Flow of mantle fluids through the ductile lower crust: Helium isotope trends," Science, vol. 318, no. 5855, pp. 1433-1436, 2007.

[24] R. Armijo, P. Tapponnier, J. L. Mercier, and H. Tonglin, "Quaternary extension in southern Tibet: field observations and tectonic implications," Journal of Geophysical Researches, vol. 91, no. B14, pp. 13803-13872, 1986.

[25] P. Tapponnier, X. Zhiqin, F. Roger et al., "Oblique stepwise rise and growth of the tibet plateau," Science, vol. 294, no. 5547, pp. 1671-1677, 2001.

[26] W. Wei, M. Unsworth, A. Jones et al., "Detection of widespread fluids in the Tibetan crust by magnetotelluric studies," Science, vol. 292, no. 5517, pp. 716-718, 2001.

[27] M. K. Clark, L. M. Schoenbohm, L. H. Royden et al., "Surface uplift, tectonics, and erosion of eastern Tibet from large-scale drainage patterns," Tectonics, vol. 23, no. 1, Article ID TC1006, 20 pages, 2004.

[28] M. Roy and L. H. Royden, "Crustal rheology and faulting at strike-slip plate boundaries 1 . An analytic model," Journal of Geophysical Research B, vol. 105, no. 3, pp. 5583-5597, 2000.

[29] E. Enkelmann, L. Ratschbacher, R. Jonckheere et al., "Cenozoic exhumation and deformation of northeastern Tibet and the Qinling: is Tibetan lower crustal flow diverging around the Sichuan basin?" Bulletin of the Geological Society of America, vol. 118, no. 5-6, pp. 651-671, 2006.

[30] R. Huang, Z. Wang, S. Pei, and Y. Wang, "Crustal ductile flow and its contribution to tectonic stress in Southwest China," Tectonophysics, vol. 473, no. 3-4, pp. 476-489, 2009.

[31] W. Wei, S. Jin, G. Ye et al., "Features of faults in the central and northern Tibetan plateau based on results of INDEPTH 
(III)-MT," Frontiers of Earth Science in China, vol. 1, no. 1, pp. 121-128, 2007.

[32] J. Sun, G. Jin, D. Bai, and L. Wang, "Sounding of electrical structure of the crust and upper mantle along the eastern border of Qinghai-Tibet Plateau and its tectonic significance," Science in China D, vol. 46, pp. 243-253, 2003.

[33] D. Alsdorf and D. Nelson, "Tibetan satellite magnetic low: evidence for widespread melt in the Tibetan crust?" Geology, vol. 27, no. 10, pp. 943-946, 1999.

[34] J. He and S. Lu, "Lower friction of the Xianshuihe-Xiaojiang fault system and its effect on active deformation around the south-eastern Tibetan margin," Terra Nova, vol. 19, no. 3, pp. 204-210, 2007.

[35] A. Nur and J. R. Booker, "Aftershocks caused by pore fluid flow?" Science, vol. 175, no. 4024, pp. 885-887, 1972.

[36] S. Steacy, S. S. Nalbant, J. McCloskey, C. Nostro, O. Scotti, and D. Baumont, "Onto what planes should Coulomb stress perturbations be resolved?” Journal of Geophysical Research B, vol. 110, no. 5, Article ID B05S15, 14 pages, 2005.

[37] B. E. Nesbitt, "Electrical resistivities of crustal fluids," Journal of Geophysical Research, vol. 98, no. 3, pp. 4301-4310, 1993.

[38] A. Pommier and E. Le-Trong, "'SIGMELTS': a web portal for electrical conductivity calculations in geosciences," Computers and Geosciences, vol. 37, no. 9, pp. 1450-1459, 2011.

[39] S. Li, M. J. Unsworth, J. R. Booker, W. Wei, H. Tan, and A. G. Jones, "Partial melt or aqueous fluid in the mid-crust of Southern Tibet? Constraints from INDEPTH magnetotelluric data," Geophysical Journal International, vol. 153, no. 2, pp. 289-304, 2003.

[40] B. R. Hacker, E. Gnos, L. Ratschbacher et al., "Hot and dry deep crustal xenoliths from Tibet," Science, vol. 287, no. 5462, pp. 2463-2466, 2000.

[41] J. Mechie, S. V. Sobolev, L. Ratschbacher et al., "Precise temperature estimation in the Tibetan crust from seismic detection of the $\alpha-\beta$ quarts transition," Geology, vol. 32, no. 7, pp. 601-604, 2004.

[42] A. Galvé, M. Jiang, A. Hirn et al., "Explosion seismic P and $S$ velocity and attenuation constraints on the lower crust of the North-Central Tibetan Plateau, and comparison with the Tethyan Himalayas: implications on composition, mineralogy, temperature, and tectonic evolution," Tectonophysics, vol. 412, no. 3-4, pp. 141-157, 2006.

[43] I. Jiménez-Munt, M. Fernàndez, J. Vergés, and J. P. Platt, "Lithosphere structure underneath the Tibetan Plateau inferred from elevation, gravity and geoid anomalies," Earth and Planetary Science Letters, vol. 267, no. 1-2, pp. 276-289, 2008. 

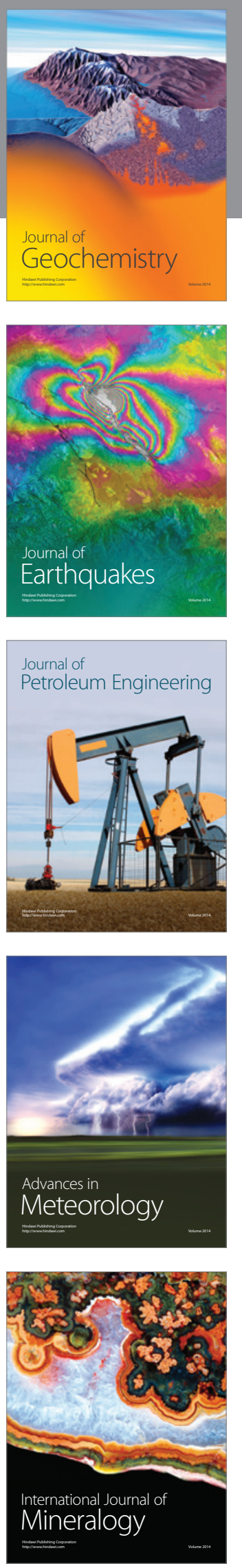
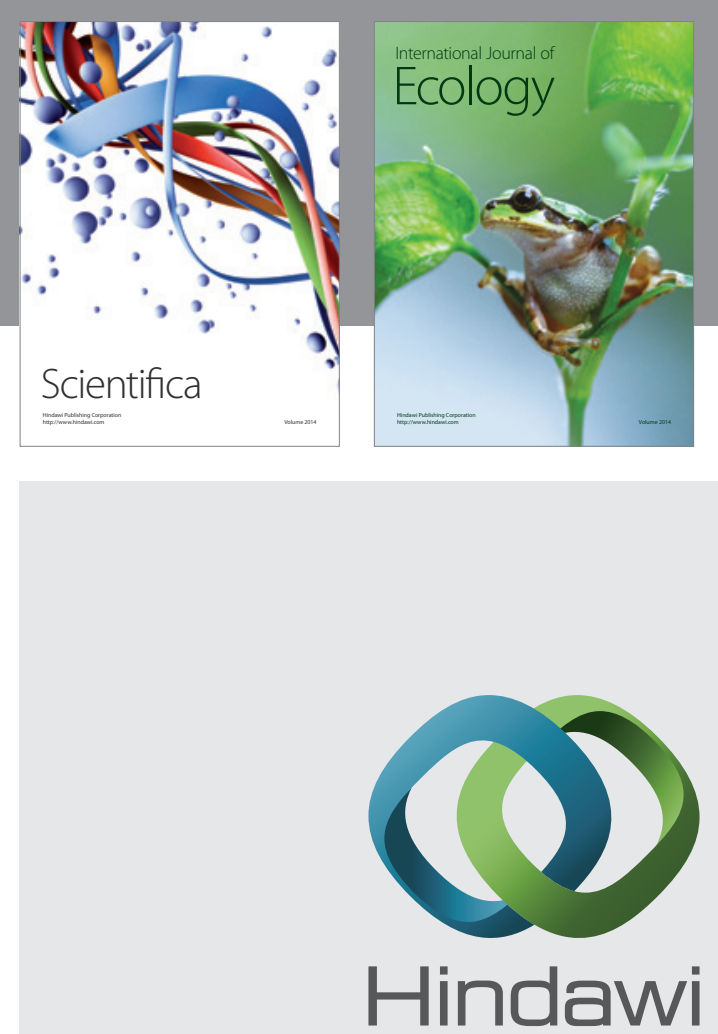

Submit your manuscripts at http://www.hindawi.com
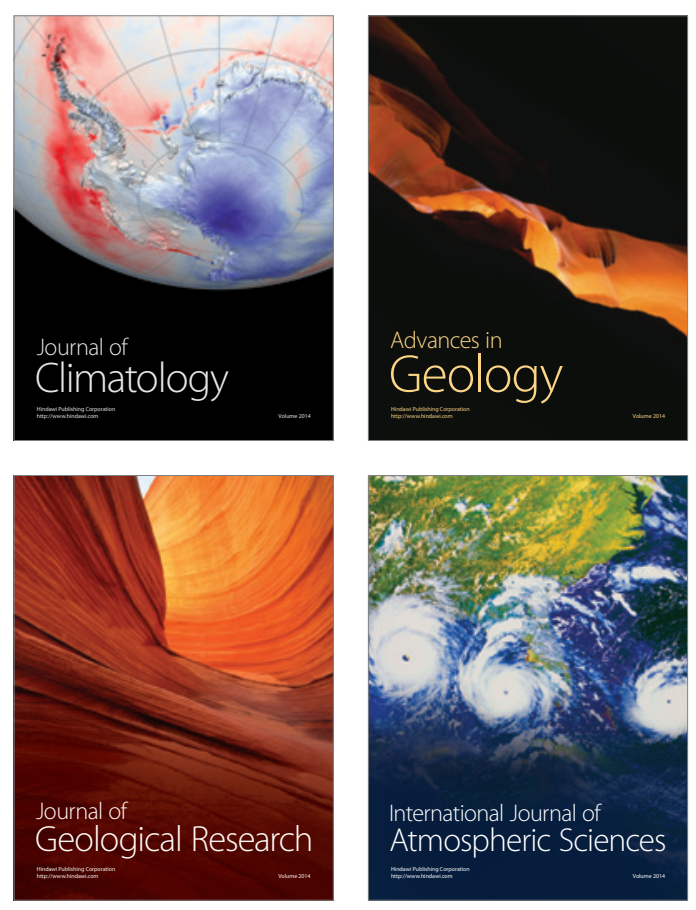
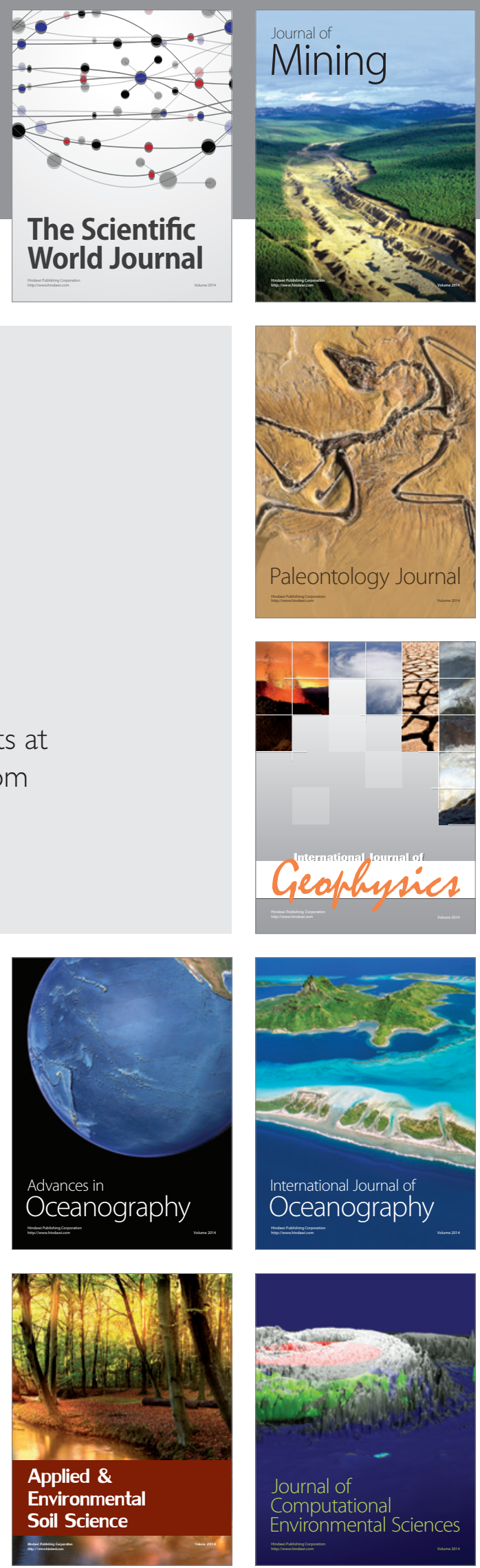